\title{
The Survey and Analysis of the Development of Catering Take-out O2O in Lingnan Normal University
}

\author{
Yafen Huang and Simei Tan \\ Life science and technological college of Lingnan Normal University, Zhanjiang, 524048 China \\ afen821026@126.com
}

Keywords: Take-out food; O2O; Lingnan Normal University; Speed of the delivery; Food safety

\begin{abstract}
In order to advance the development of take-out $\mathrm{O} 2 \mathrm{O}$, the essay using internet questionnaire to survey the present situation and developments of Take-out $\mathrm{O} 2 \mathrm{O}$ in Lingnan Normal University. The results show that there are food safety, environmental pollution, slow delivery speed, bad taste to be solved besides of advantages. Finally the essay puts forward some recommendations to solve these problems, such as: improving the integrity mechanisms, improving security barriers, strengthening environmental protection awareness, promoting distribution of team-building, promoting the standardization of Chinese fast food dishes, with a view to promoting the healthy development of Take-out $\mathrm{O} 2 \mathrm{O}$.
\end{abstract}

\section{Introduction}

The Background to the Topic. AS the coming of electronic commerce, all kinds of industries have changed a lot. In the development, $\mathrm{O} 2 \mathrm{O}$ business model arises at the historic moment [1]. $\mathrm{O} 2 \mathrm{O}$ all called Online To Offline, in Chinese, it means from Online to Offline, refers to" with the combination of the Internet as a Offline trading platform", It mainly provides the service life of business model. That is to say, $\mathrm{O} 2 \mathrm{O}$ merchants are generally has the offline stores, consumers through the network platform, the combination of online and offline resources for consumption.

Therefore, the article studies the campus, and survey on Lingnan normal university as the object, in the form of questionnaire survey, to stude the take-out $\mathrm{O} 2 \mathrm{O}$ in present situation and influence of colleges and universities, and the analyzes its development[2].

The Aim of the Investigation. According to study the current situation of Lingnan normal university, the article is to find out the existing problems, and put forward the solution to suit the development of take-away O2O.In the past articles, there are rare contents about the O2O, especially the campus. This article is the first one to study it.

\section{Questionnaire Design and Survey Method}

Questionnaire Content. In order to ensure the rationality of the questionnaire, the survey includes interview, reference documents and questionnaire survey .First of all, through the random part of the students as an object, interview them and design the question, and then investigate the students and then adjust the question according to the answer and advice from the students.

This questionnaire is given priority to multiple choice, including 20 questions, involving the take-away $\mathrm{O} 2 \mathrm{O}$ in the school situation, positive and negative effects, the development Suggestions, etc.

\section{Survey Method and Data Collection}

Literature Data Method. According to review the Internet, newspapers, degree thesis, important meeting documents, trade journals, the article learned the take-away $\mathrm{O} 2 \mathrm{O}$ present situation and development theory. And through the comparative analysis and summary, The article puts forward their own research methods and theoretical basis.

The Network Questionnaire Survey. This survey mainly adopts the network questionnaire survey, using the platform"sujump". 
Data Collection and Processing. According to the Email, QQ and Wechat, the investigation includes 200 papers, and returned 200 papers. In all this papers, 179 papers show that they use the take-out O2O, these are the main subjects. We use Microsoft Excel 2010 to process the data.

Sample Selection. The students from Lingnan normal university.

\section{The Results of the Survey}

Analyses the Current Situation of the Take-away 020. The Situation Analysis of the Use of the Take-away $\mathrm{O} 2 \mathrm{O}$. According to investigation, in 200 respondents, $37.5 \%$ of students have used but now use less take-away $\mathrm{O} 2 \mathrm{O}$, now occasionally use ratio of $36 \%$, only $16 \%$ of students now often use, and $10.5 \%$ of students do not use.

According to interview the no use students, we can see that the reasons: the roommates replace them, the take-ou is nutrionless, and they book by telephone.

The Proportion of Take-out 020 Use Crowd Analysis. According to investigation, there are $65 \%$ are females, because the proportion of boy and girl in this school is 3:7.

Analysis of the Usage of Take-away 020 Platform. On January 28, 2016, analysis think-tank released <China Internet food take-away market research report 2016>, in the fourth quarter of 2015, it studied the student campus trade share catering takeout. According to its monitoring, Meituan take-away occupy $43.4 \%$, hungry? $36.2 \%$, baidu take-away is $7.2 \%$, other $13.2 \%$.

In our investigation, in campus, there are $49.16 \%$ choosing Meituantake-away, hungry? $42.46 \%$, baidu take-away $5.03 \%$, only $3.35 \%$ choosing other platform, such as mouth take-away, take-away superman.

\section{The Frequency of Using the Take-away $\mathrm{O2O}$ and the Analysis of Students' Average Consumption Level}

Through questionnaire, most of the students use the frequency of the take-away $\mathrm{O} 2 \mathrm{O}$ mainly for 1 to 3 times a week, the average cost for 5 to 10 yuan each time, there are $39.11 \%$ of the students spend an average of 10 to 20 yuan. This reflects the small and medium-sized catering enterprises can provide economical and plenty of food, nutrition in order to attract the students' consumption.

The Consumption Category Analysis of the Take-away 02O. According to investigation, 91.06\% of the students chose the Chinese fast food, and then the western fast food, such as KFC, pizza hut, about3.91\%. We can see that the Chinese fast food has a large market potential, take-out platform can absorb more Chinese style fast-food restaurants.

The Time Analysis of Using the Take-away 020. According to the survey, $70.39 \%$ students choose at noon, the reason mainly is: 1 , students wait for a long time in dining room; 2 , students miss dinner time. So the catering businesses should increase the speed of delivery, meet the demand of the students' dining.

\section{The Analysis of the Existing Problem of Take-away O2O}

The Level of the Problem. According to the investigation, the obvious problems of the take-away $\mathrm{O} 2 \mathrm{O}$ are below: room waiting time is too long, food insecurity, food taste bad, the food goods wrong version. Not obvious problems mainly are food distribution error and distribution price is not reasonable, staff service attitude is poor, payment is not safe. Among these problems, especially in the room waiting for a long time and not safe food two the most serious problem [3].

Influence of Take-out O2O Food Safety and Control Problems of Analysis. The take-away o2o platform rarely supervises the dealer business qualification review, the threshold is too low, so it is easy to become a hotbed of development "black workshop". Food hygiene and safety hidden trouble and crisis seriously affected the development of the take-away $\mathrm{O} 2 \mathrm{O}$, became the take-away market greatly hinder the development. 


\section{Analysis and Discussion}

The Reason Analysis of the Existing Problem of Take-away O2O. At presents, all the problems, in addition to the government regulation, the students' personal quality, are mainly caused by a defective delivery platform and catering businesses themselves:

(1) Lack of consciousness of social responsibility and integrity. Delivery platform and merchant's viewpoint of social benefit consciousness, the good faith is weak, ignore the importance of food safety, easy to cause, the way of doing illegal profit.

(2) Delivery platform management system has defects, lack of necessary guidance system. Delivery platform not sign the agreement shall practice a system of strict review of the dealer business qualification, restaurant in the threshold is lower, the more difficult to guarantee the quality of businesses and services. Service chain is too long lead to unclear responsibility. From online to offline, if customers appear food safety problems, issues of liability shall be borne by the who has no clear instructions.

(3) The vicious competition between delivery platform. Each big platform is not according to their own characteristics innovative business model, to improve their comparative advantage, in general the degree of similarity between each delivery platform, business mode is too single, without actually improve user experience, ignoring the differential marketing, lead to users to repeat purchase intention is not strong[4].

(4) The delivery service is not perfect, the transportation of food has problem. The personnel of take-out meals are lack of service consciousness, safe consciousness. The hygiene of transportation box and food packaging in the process of transportation is not guaranteed.

(5) The lack of food hygiene and safety awareness. Food hygiene problems has been the ills of the food industry. The report of the problem influenced the take-out platform.

(6) There is no standardized production, the stability of the food quality is weak. Consumer's satisfaction is closely related to the food quality. When consumers find the food tastes differ big or goods wrong version, psychological gap is self-evident.

\section{Discussion and Advice}

To further promote the benign development of the take-away $\mathrm{O} 2 \mathrm{O}$, the survey puts forward the following Suggestion.

Improve the Delivery Platform and Business Sense of Responsibility, Strengthen Environmental Protection Consciousness. The increase of take-out lunch boxes to campus environment has brought the unbearable load. Some restaurant in order to reduce the production cost, the use of cheap plastic packaging containing harmful substances. This for packing food, not only can affect the body health, more can bring serious damage to the environment. To control this kind of phenomenon, take-out platform and merchants should take the initiative to take responsibility, make the necessary action to environmental protection. Choose biodegradable materials for take-out packaging, minimize environmental pollution. In addition, take-out platform can establish agreement with school logistics department, set up specialized in college campus, dormitory right amount of recycling bin, assign special personnel to recycle.

Improve the Honesty Mechanism, Improve the Good Faith Consciousness. The information transmission distortion exists in the take-out platform. It will beauty the product information, and on the other hand, the businessman delivered the fate information of the food in order to improve the sales. The consumers hate false information. If this exists, it will lose the trust of the consumers, so delivery platform integrity awareness, improve the honesty mechanism, constraint on the rewards and punishment system itself and merchants, the good faith management [5].

Perfect Management System and Improve the Safety Inspection Threshold. Delivery platform should improve their own management system as soon as possible, formulate relevant examination content, when the review is not only to review the business license and hygiene license, approval documents and other relevant certificates; To review the essence, to send staff visit the merchant's production and business operation condition and health condition, on the site with the 
introduction of the merchants had better be illustrated, cooperation should be on the merchant's address, business licenses, health conditions, quality condition fully, to introduce more food source, after hutch situation, production process and other detailed information, if you can put a business as a meal kitchen video is more reliable. Help enterprises to track consumer experience, perfecting the internal problems existing in the catering enterprises in time, in addition, the platform also should have a complete elimination mechanism, used for regulatory cooperation business, improve the quality of the merchant's business.

Promote the Distribution Team Building, Improve the Delivery Speed. Now, for students, the speed is the most thing. In 2015, the major platform to build logistics team, prototype has been seen, but the effect remains to be strengthened. In addition, due to the weather, traffic, route of optimization, and many other uncertain factors, cause a lot of the time delivery want fast delivery has the certain difficulty. At that time, delivery platform should have corresponding emergency countermeasures, such as reserve in advance students part-time, trained and qualified mount guard after, at the height of every much, the above many situation can avoid [6]. In addition, take-away business also needs to be strengthened in the shipping details, such as separate rice and food packaging in order to make sure the food delicious, use incubator distribution, etc.

Ensure Food Hygiene, and Promote the Diversification. Food hygiene is an important link to safeguard the quality of take-out food and take-away platform and brand trust. Exposure of the take-away food safety problems frequently, such consumption group of a piece of my mind. Each big platform should exercise supervision duty, strengthen health awareness training to the businessman, and the institutional constraints, to ensure food hygiene and safety. Food diversification is an important factor to consumers consider the food consumption. Take-away O2O services is take-away food, the diversification of the food helps to improve the take-away $\mathrm{O} 2 \mathrm{O}$ orders and consumer satisfaction. In the take-away $\mathrm{O} 2 \mathrm{O}$ market, emphasize the varieties of dishes can enhance the user experience of consumption, such as regular updates menu, highlight out selling $\mathrm{O} 2 \mathrm{O}$ need food diversification of product strategy form favorable market competitiveness.

Promote the Chinese Fast Food Standardization, Stable Food Quality. Standardization is a key to guarantee electric dealer market in order to. Development of one of the obstacles of the take-away $\mathrm{O} 2 \mathrm{O}$ model is the merchants of the wraps brands are more diverse, classification is not clear, the same kind of diet in the operation and practice of practice and not standard, to a large extent hindered the application of the $\mathrm{O} 2 \mathrm{O}$ mode [7]. So, in the future development of domestic food and beverage $\mathrm{O} 2 \mathrm{O}$ or take-away $\mathrm{O} 2 \mathrm{O}$, the developing mode of Chinese food, food manufacturing process must be gradually towards standardization, standardization, let the consumer feel consistent quality. Therefore delivery platform and catering businesses should work together to promote the Chinese food standardization construction, through the science and technology informatization, in raw materials procurement, food production to achieve standardization, procedural, stable production.

\section{Conclusion}

From emergence to development, gradually mature, for college students, Take-away $\mathrm{O} 2 \mathrm{O}$ can be said to meet the basic demand of the meal, but the survey results show that the take-away market still exists many problem that should not be ignored: food safety, environmental pollution, slow speed of delivery, poor food taste, food goods wrong version... We believe that the risk and opportunity always coexist, as long as constantly combining theory with practice, , take-away $\mathrm{O} 2 \mathrm{O}$ will have a bright future.

\section{References}

[1] Chun-e Du. O2O mode catering takeout students consumers analysis: the market based on the empirical study of Hebei normal university [J].News knowledge, 2015,04:23-24. 
[2] Cronin, J. J, Brady, M. K., \& Hult, G T. M. Assessing the effects of quality, value, and customer satisfaction on consumer behavioral intentions in service environments. Journal of Retailing, 2000, 76(2), 193-218.

[3] Tovar Laura, al. Migration studies to assess the safety in use of a new antioxidant active packaging.[J]. Salafranca Jesús, Sánchez Cristina et .Journal of Agricultural and Food Chemistry.2005, 53(13).

[4] Li-ying Yang. Reserch on the management mode of university city centre network research [D]. Changchun university of science and technology, 2014:34-35.

[5] Zhang fang. Mobile Internet situation catering service contact research effect on customer behavioral intention [D].Zhejiang University, 2015:114-116.

[6] Yu-han Li. Based on the use and satisfy, college students using Meituan take-out APP research [D].Jiangxi normal university, 2015: 38-39.

[7] Sha-sha Wang. Study on the O2O e-commerce mode development research in our country [D].Shandong normal university, 2015: 41-42. 